\title{
Systematic hardness measurements on mixed and doped crystals of rubidium halides
}

\author{
D B SIRDESHMUKH*, T KUMARA SWAMY, P GEETA KRISHNA and \\ K G SUBHADRA \\ Physics Department, Kakatiya University, Warangal 506 009, India
}

MS received 7 August 2002; revised 29 November 2002

\begin{abstract}
Efforts are made to improve the hardness of rubidium halide crystals by (i) solid solution hardening and (ii) impurity hardening. Systematic microhardness measurements have been made on rubidium halide mixed crystals ( $\mathrm{RbBr}-\mathrm{RbI}$ and $\mathrm{KI}-\mathrm{RbI}$ ) and rubidium halide crystals doped with $\mathrm{Sr}^{2+}$ ions. The composition dependence of the hardness of mixed crystals follows the law $\Delta H_{\mathrm{V}}=K x(1-x)$, where $\Delta H_{\mathrm{V}}$ is the enhancement in hardness, $K$ a constant and $x$ and $(1-x)$ the concentrations of the first and second component of the mixed crystals, respectively. The hardness of doped crystals increases with the concentration $C$ of the dopant according to the law, $\Delta H_{\mathrm{V}}=k C^{m}$, where $k$ and $m$ are constants. The relative efficacy of the two methods of hardening is discussed.
\end{abstract}

Keywords. Hardness; rubidium halide mixed crystals; doped rubidium halide crystals.

\section{Introduction}

Alkali halide crystals have several practical applications viz. as radiation detectors, as $\mathrm{X}$-ray and neutron monochromators, as infrared optical components and also as laser host materials (Sirdeshmukh et al 2001a).

A physical property that limits the utility of alkali halides as device materials is their low hardness. Armington et al (1973) discussed two methods of improving the hardness of alkali halides: (i) solid solution hardening and (ii) impurity hardening. The hardness of several alkali halide mixed crystals is reviewed by Hari Babu and Subba Rao (1984). Chin et al (1973) studied the effect of divalent impurities (doping) on the hardness of sodium and potassium halides.

The rubidium halides have useful infrared transmission characteristics and have, recently, been found (Thomas et al 1994) to be efficient X-ray information storage sensors. Earlier studies from this laboratory (Thirmal Rao and Sirdeshmukh 1991) have shown that among the alkali halides with $\mathrm{NaCl}$ structure, for which hardness values are known, the rubidium halides have the lowest hardness. This paper reports results of hardness measurements aimed at improving the hardness of rubidium halide crystals both by solid solution hardening and impurity hardening. The mixed crystal systems chosen for this study are $\operatorname{RbBr}_{x} \mathrm{I}_{(1-x)}$ and $\mathrm{K}_{x} \mathrm{Rb}_{(1-x)} \mathrm{I}$ and the impurity chosen for doping is $\mathrm{Sr}^{2+}$.

\footnotetext{
*Author for correspondence
}

\section{Experimental}

\subsection{Crystal growth and characterization}

Single crystals were grown by using a minifurnace described in detail elsewhere (Srinivas et al 1999). For the mixed crystals, the two components were taken in the required proportion. For growing $\mathrm{Sr}^{2+}$ doped crystals, different amounts of $\operatorname{Sr}\left(\mathrm{NO}_{3}\right)_{2}$ were added to the rubidium halides before melting.

The solidified ingot yielded single crystals with several mms linear dimensions. Their excellent cleavage itself was an evidence of single crystallinity. In addition, X-ray Laue photographs were obtained which showed spots with the expected distribution. X-ray powder diffractograms showed that the mixed crystals had a single phase.

Different techniques were employed to determine the compositions. The composition of the $\operatorname{RbBr}_{x} \mathrm{I}_{(1-x)}$ mixed crystals was determined by the method of potentiometric titration. In the case of the $\mathrm{K}_{x} \mathrm{Rb}_{(1-x)} \mathrm{I}$ mixed crystals, the lattice constants were determined from the X-ray diffractograms and these were used to estimate the composition assuming Vegard's law (Bosch et al 1972). To determine the concentration of $\mathrm{Sr}^{2+}$ in the doped crystals, the technique of atomic absorption spectroscopy was used and a 902 GBC double beam atomic absorption spectrometer was employed.

\subsection{Vickers microhardness measurement}

Microhardness measurements were made with the help of a Leitz-Wetzlar Miniload Hardness Tester fitted with a 
Vickers diamond pyramidal indenter. The Vickers hardness $\left(H_{\mathrm{V}}\right)$ was calculated from the relation

$$
H_{\mathrm{V}}=(1854 \cdot 4) P / d^{2} \text {, }
$$

where $P$ is the applied load and $d$ the length of the diagonal of the indentation mark. With $P$ in $\mathrm{g}$ and $d$ in $\mu \mathrm{m}$, the units of $H_{\mathrm{V}}$ turned out to be $\mathrm{kg} / \mathrm{mm}^{2}$. Indentations were carried out at different loads in the range 5-50 g. A load dependence of hardness was observed which was corrected by the procedure discussed by Sirdeshmukh et al (2000, 2001b). The method of error evaluation was given in a recent paper (Sirdeshmukh et al 2002).

\section{Results and discussion}

\subsection{Hardness of mixed crystals}

The Vickers microhardness values for the $\operatorname{RbBr}_{x} \mathrm{I}_{(1-x)}$ and $\mathrm{KBr}_{x} \mathrm{I}_{(1-x)}$ mixed crystals are given in table 1 for several compositions and are also shown in figure 1. In both cases the microhardness shows a nonlinear composition dependence with positive deviations from linearity. In the intermediate composition range, the hardness of mixed crystals is larger than the values of the end members.

We define $\Delta H_{\mathrm{V}}$ as the deviation of the measured hardness of a mixed crystal from the value expected from additive behaviour. These $\Delta H_{\mathrm{V}}$ values are included in table 1 and are also shown in figure 2. The $\Delta H_{\mathrm{V}}$ vs $x$ curves are in the form of inverted parabolas. The two mixed crystal systems studied in this work and also the $\mathrm{RbCl}-\mathrm{RbBr}$ system studied earlier (Thirmal Rao and Sirdeshmukh 1991) follow the equation

$$
\Delta H_{\mathrm{V}}=K x(1-x)
$$

where $K$ is a constant. The values of $K$ obtained by fitting the experimental data to (2) are given in table 2 .

Table 1. Values of the Vickers hardness $\left(H_{\mathrm{V}}\right.$ in $\left.\mathrm{kg} / \mathrm{mm}^{2}\right)$ and the deviation $\left(\Delta H_{\mathrm{V}}\right.$ in $\left.\mathrm{kg} / \mathrm{mm}^{2}\right)$ of the observed values from the additive values for the mixed crystals (error in $H_{\mathrm{V}}, 0.6$

\begin{tabular}{|c|c|c|c|c|c|}
\hline \multicolumn{3}{|c|}{$\mathrm{RbBr}_{x} \mathrm{I}_{1-x}$} & \multicolumn{3}{|c|}{$\mathrm{K}_{x} \mathrm{Rb}_{1-x} \mathrm{I}$} \\
\hline$x$ & $H_{\mathrm{V}}$ & $\Delta H_{\mathrm{V}}$ & $x$ & $H_{\mathrm{V}}$ & $\Delta H_{\mathrm{V}}$ \\
\hline 0 & $6 \cdot 01$ & 0 & 0 & $6 \cdot 01$ & 0 \\
\hline $0 \cdot 27$ & $21 \cdot 33$ & $14 \cdot 2$ & $0 \cdot 1$ & $10 \cdot 1$ & $4 \cdot 4$ \\
\hline 0.39 & $23 \cdot 36$ & $16 \cdot 8$ & $0 \cdot 19$ & $11 \cdot 5$ & $5 \cdot 5$ \\
\hline 0.48 & $25 \cdot 22$ & 17.9 & $0 \cdot 33$ & $13 \cdot 23$ & $6 \cdot 7$ \\
\hline 0.59 & $25 \cdot 27$ & 18 & $0 \cdot 4$ & $13 \cdot 37$ & $6 \cdot 8$ \\
\hline 0.69 & $23 \cdot 40$ & $16 \cdot 2$ & $0 \cdot 5$ & $13 \cdot 44$ & $6 \cdot 7$ \\
\hline 0.78 & $22 \cdot 01$ & 13 & $0 \cdot 64$ & $12 \cdot 41$ & $5 \cdot 8$ \\
\hline \multirow[t]{3}{*}{1} & $8 \cdot 10$ & 0 & 0.74 & $12 \cdot 73$ & $4 \cdot 7$ \\
\hline & & & $0 \cdot 87$ & $10 \cdot 30$ & $2 \cdot 9$ \\
\hline & & & 1 & $7 \cdot 00$ & 0 \\
\hline
\end{tabular}
$\mathrm{kg} / \mathrm{mm}^{2}$ ).
From (2), it can be seen that the maximum value of $\Delta H_{\mathrm{V}}$ occurs at $x=0.5$ and $\left(\Delta H_{\mathrm{V}}\right)_{\max }=0.25 \mathrm{~K}$. Thus, $K$ is a measure of the maximum hardening. In view of this significance of $K$, we may conclude from the $K$ values given in table 2 that addition of RbI has a greater hardening

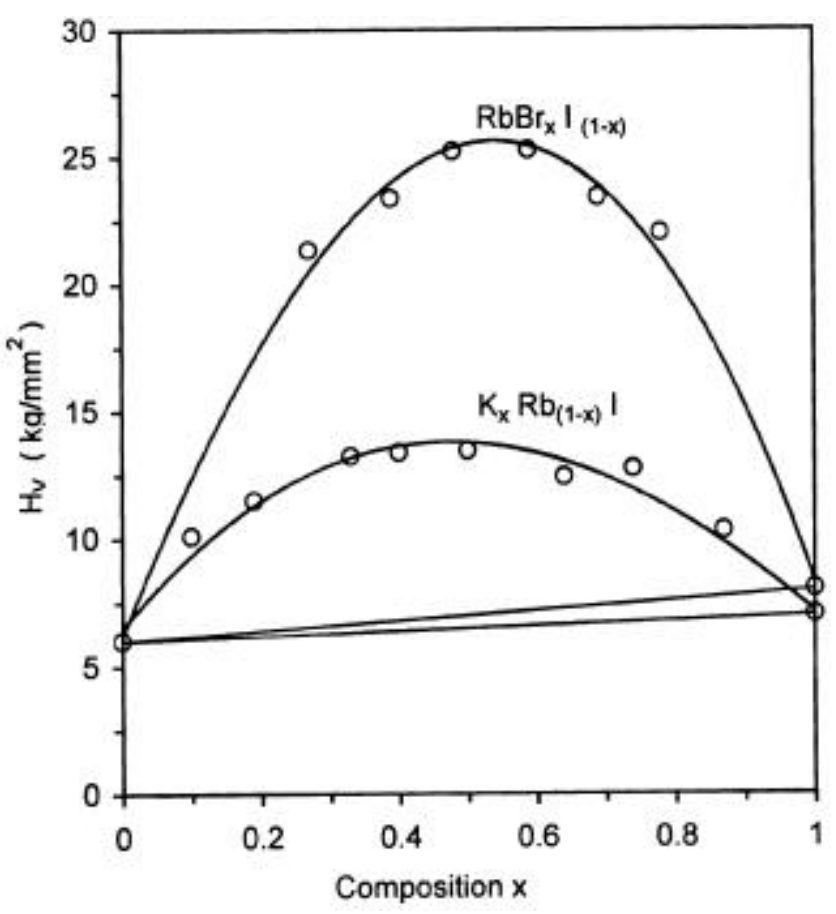

Figure 1. Plot of hardness, $H_{\mathrm{V}}$, against the composition $x$ for the mixed crystals.

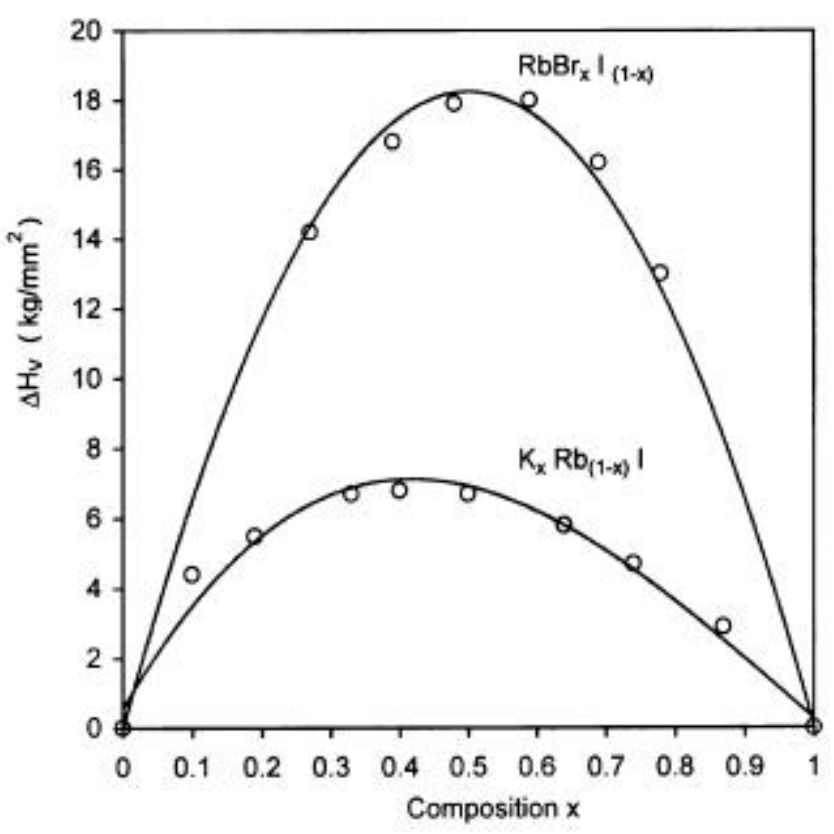

Figure 2. Plot of $\Delta H_{\mathrm{V}}$ vs composition $x$ for the mixed crystals. 
effect on $\mathrm{RbBr}$ than the addition of $\mathrm{RbCl}$. Similarly addition of $\mathrm{RbBr}$ has a far greater hardening effect on $\mathrm{RbI}$ than the addition of KI.

Sirdeshmukh and Srinivas (1986) pointed out in their review paper that the replacement of an ion by another ion of different size (the "size effect") in mixed crystals results in a highly non-linear composition variation in properties like the Debye-Waller factor, the dislocation density and hardness. Subba Rao and Hari Babu (1978) pointed out that in a mixed crystal, lattice interactions as well as the disorder due to size effect contribute to the hardness. On the other hand, Shrivastava (1980) considered the effect of the presence of substituted ions on the dislocation mobility and on the hardness. Both these approaches result in an equation exactly similar to (2) for the hardness of a mixed crystal in terms of its composition.

The experimental observations regarding the hardening of $\mathrm{RbBr}$ and $\mathrm{RbI}$ mixed crystals can be discussed qualitatively in terms of (2). The ionic radii of $\mathrm{K}^{+}, \mathrm{Rb}^{+}, \mathrm{Cl}^{-}, \mathrm{Br}^{-}$ and $\mathrm{I}^{-}$are $1.51,1.65,1.65,1.80$ and $2.01(\AA)$, respectively (Sirdeshmukh et al 2001a). In $\mathrm{RbCl}-\mathrm{RbBr}$ mixed crystal the size difference is $0.15 \AA$ whereas in $\mathrm{RbBr}$ $\mathrm{RbI}$, it is $0.21 \AA$. Since hardening is due to the size effect, it is more in the latter than in the former. Similarly, in RbI-KI the size difference is $0 \cdot 14 \AA$ whereas in $\mathrm{RbI}-\mathrm{RbBr}$ it is $0.21 \AA$. Again, the hardening is larger in the latter.

\subsection{Hardness of doped crystals}

There are several earlier studies on the hardness of alkali halide crystals doped with divalent ions. Dryden et al (1965) measured the critical resolved shear stress (which is related to the hardness) of $\mathrm{NaCl}$ doped with $\mathrm{Ca}^{2+}$ and $\mathrm{Mn}^{2+}, \mathrm{KCl}$ doped with $\mathrm{Ca}^{2+}$ and $\mathrm{Ba}^{2+}$ and $\mathrm{LiF}$ doped with $\mathrm{Mg}^{2+}$. In all these cases they found an increase in hardness proportional to $C^{2 / 3}$, where $C$ is the molar concentration of the impurity. Chin et al (1973) measured the microhardness of $\mathrm{NaCl}, \mathrm{NaBr}, \mathrm{KCl}$ and $\mathrm{KBr}$ doped with $\mathrm{Ca}^{2+}, \mathrm{Sr}^{2+}$ and $\mathrm{Ba}^{2+}$ dopants. They observed that the increase in hardness (i) is proportional to $C^{1 / 2}$ and (ii) is independent of the host lattice. There is no reported study of the effect of doping on the hardness of the rubidium halides. In the present study the effect of addition of $\mathrm{Sr}^{2+}$

Table 2. Values of the constant, $K$ (in $\mathrm{kg} / \mathrm{mm}^{2}$ ) in (2).

\begin{tabular}{ll}
\hline System & $K$ \\
\hline RbCl-RbBr* & 55 \\
RbBr-RbI & 73 \\
KI-RbI & 27 \\
\hline
\end{tabular}

*From Thirmal Rao and Sirdeshmukh (1991). ions on the hardness of rubidium halides is studied. The results are given in table 3 and are also shown in figure 3. It is seen that the hardness increases with increase in concentration $C$ of the dopant. The results were fitted to the relation

$$
\Delta H_{\mathrm{V}}=k C^{m}
$$

where $\Delta H_{\mathrm{V}}$ is the enhancement in hardness and $k$ and $m$ are constants; values of $k$ and $m$ are given in table 4. On comparing the present results with the results of Chin et al (1973) on the hardness of sodium and potassium halides, it is noted that the observed value of $m(\sim 0 \cdot 6)$ is close to the value of 0.5 obtained by Chin et al (1973) and, theoretically, by Gilman (1974). On the other hand, the hardening is dependent on the host lattice increasing in the sequence $\mathrm{RbI}-\mathrm{RbBr}-\mathrm{RbCl}$, unlike in the case of the sodium and potassium halides.

Fleischer (1962) developed a model to account for the hardening of alkali halides by divalent impurities. The divalent impurities are strongly attracted by positive ion vacancies resulting in large tetragonal distortions. A moving dislocation experiences a force due to the distortion. The resulting expression for the flow stress (which is a measure of the hardening) is proportional to $C^{1 / 2}$, where $C$ is the concentration of the impurity. Considering the approximations in his model, Fleischer admit-

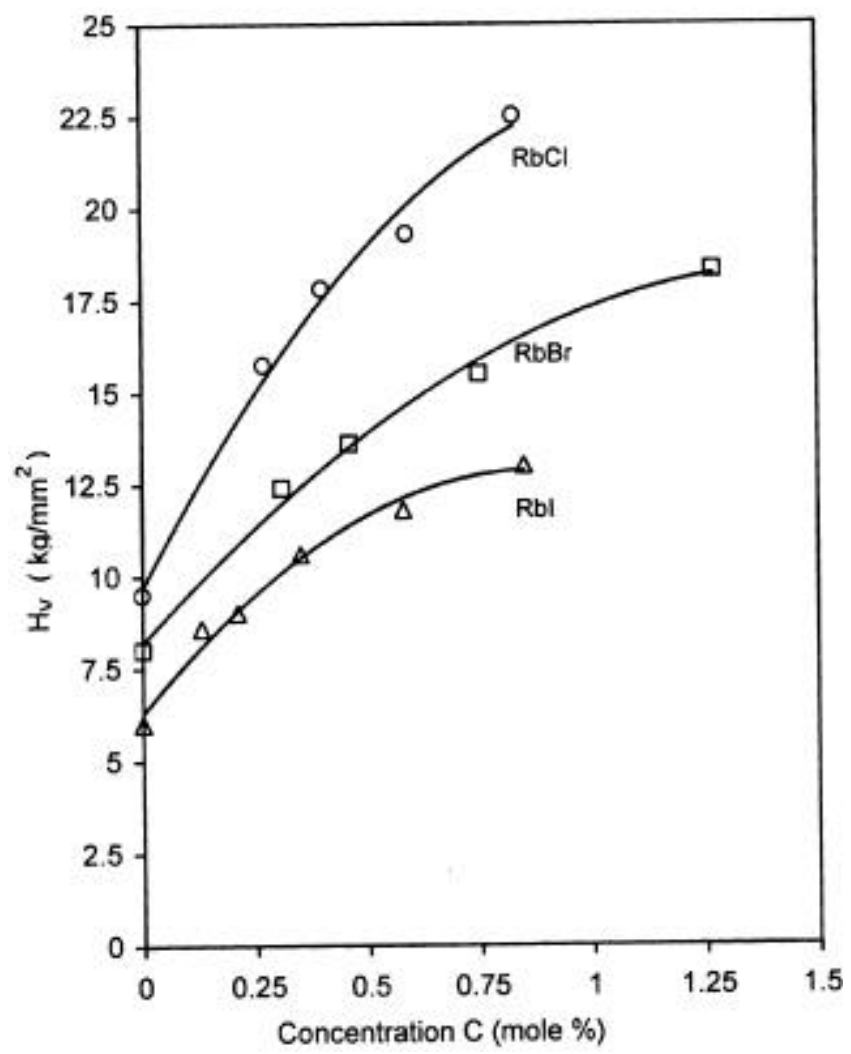

Figure 3. Plot of $H_{\mathrm{V}}$ as a function of concentration, $C$ of $\mathrm{Sr}^{2+}$ ions in the doped crystals. 
Table 3. Values of Vickers hardness $\left(H_{\mathrm{V}}\right)$ for the rubidium halides at different concentrations of $C$ of the $\mathrm{Sr}^{2+}$ ions (error in $H_{\mathrm{V}}, 0.6 \mathrm{~kg} / \mathrm{mm}^{2}$ ).

\begin{tabular}{lcr}
\hline Crystal & $\begin{array}{c}C \\
(\mathrm{~mole} \%)\end{array}$ & $\begin{array}{c}H_{\mathrm{V}} \\
\left(\mathrm{kg} / \mathrm{mm}^{2}\right)\end{array}$ \\
\hline $\mathrm{RbCl}$ & 0 & $9 \cdot 50$ \\
& $0 \cdot 27$ & 15.75 \\
& $0 \cdot 40$ & $17 \cdot 82$ \\
& $0 \cdot 59$ & $19 \cdot 30$ \\
& $0 \cdot 83$ & 22.50 \\
$\mathrm{RbBr}$ & 0 & $8 \cdot 10$ \\
& $0 \cdot 31$ & 12.40 \\
& 0.46 & 13.61 \\
& 0.75 & 15.52 \\
& 1.27 & 18.30 \\
$\mathrm{RbI}$ & 0 & 6.01 \\
& $0 \cdot 13$ & 8.58 \\
& 0.21 & 9.00 \\
& 0.35 & 10.61 \\
& 0.58 & 11.81 \\
& 0.85 & 13.01 \\
\hline
\end{tabular}

Table 4. Values of the constants, $k$ (in $\mathrm{kg} /$ $\left.\mathrm{mm}^{2}\right)$ and $m$ in (3).

\begin{tabular}{lrc}
\hline Crystal & \multicolumn{1}{c}{$k$} & $m$ \\
\hline $\mathrm{RbCl}$ & $14.36 \pm 1.00$ & $0.63 \pm 0.05$ \\
$\mathrm{RbBr}$ & $8.96 \pm 1.00$ & $0.60 \pm 0.05$ \\
$\mathrm{RbI}$ & $8.15 \pm 1.00$ & $0.62 \pm 0.05$ \\
\hline
\end{tabular}

ted that the values of hardening predicted by his theory can be accurate "to within no better than a factor of two".

Gilman (1974) criticized Fleischer's model and proposed a theory in which hardening is associated with the change in electrostatic energy that occurs when a moving dislocation shears a divalent ion-cation vacancy complex. According to this model the hardening is proportional to $B C^{1 / 2}$ where the hardening coefficient, $B$, is given by

$$
B=4 \cdot 7 e^{2}\left(\varepsilon a^{4}\right)^{-1},
$$

here $e$ is the electron charge, $\varepsilon$ the static dielectric constant and $a$ the lattice constant of the host crystal. As Gilman's immediate interest was in providing an explanation for the results of Chin et al, he adopted the unusual procedure of assuming average values for the static dielectric constant and the lattice constants of the four alkali halide crystals $(\mathrm{NaCl}, \mathrm{NaBr}, \mathrm{KCl}, \mathrm{KBr})$ and obtained an average value for $B$ which was in fair agreement with the experimental value.

Chin et al have concluded that the impurity hardening observed by them in their study of sodium and potassium halides is independent of the host crystal. However, a close look at their diagrams reveals that the data points for each crystal lie on different plots with slightly different slopes which means that the hardening is not altogether independent of the host lattice. Further, calculation of the term $\left(\varepsilon a^{4}\right)^{-1}$ for the rubidium halides using individual values for $\varepsilon$ and $a$ (in $\AA$ ) from literature (Sirdeshmukh et al 2001a) yields values $1 \cdot 1,0.96$ and 0.73 (all in $10^{-4}$ ) for $\mathrm{RbCl}, \mathrm{RbBr}$ and $\mathrm{RbI}$, respectively indicating that the hardening expected from Gilman's theory is host-dependent increasing in the sequence $\mathrm{RbI}-\mathrm{RbBr}-$ $\mathrm{RbCl}$. Our results are thus consistent with Gilman's theory.

\subsection{Comparative efficacy of the two methods of hardening}

Armington et al (1973) pointed out that the optical absorption in the mixed crystals is not different from that in the pure crystals and, on the other hand, doping tends to form precipitates affecting the optical clarity. In the present study, although optical absorption was not measured, visual examination did not reveal any significant difference in the optical clarity of the mixed and doped crystals.

We have succeeded in improving the hardness of rubidium halides by $100-300 \%$ by the methods of solution hardening and impurity hardening. With regard to the relative efficacy of the two methods, the hardening is more pronounced in the doped crystals than in the mixed crystals. Thus, for instance, whereas a concentration of 0.1 mole $\%$ of $\mathrm{Sr}^{2+}$ increases the hardness of RbI by about $40 \%$, the same amount of KI in RbI increases the hardness of RbI by only $10 \%$.

\section{Conclusions}

Vickers hardness measurements have been made on $\operatorname{RbBr}_{x} \mathrm{I}_{(1-x)}$ and $\mathrm{KBr}_{x} \mathrm{I}_{(1-x)}$ mixed crystal systems. The composition dependence of hardness is nonlinear and the enhanced hardness, $\Delta H_{\mathrm{V}}$, follows the law: $\Delta H_{\mathrm{V}}=K x(1-x)$, where $K$ is a constant. The hardness of $\mathrm{RbBr}$ is affected more by addition of $\mathrm{RbI}$ than the addition of $\mathrm{RbCl}$ while the hardness of $\mathrm{RbI}$ is affected more by the addition of $\mathrm{RbBr}$ than by the addition of KI. This is explained in terms of the relative sizes of the mixing ions. Hardness measurements on $\mathrm{Sr}^{2+}$ doped rubidium halides show that there is an enhancement of $\Delta H_{\mathrm{V}}$ which follows the law, $\Delta H_{\mathrm{V}}=k C^{m}$, where $C$ is the concentration and $k$ and $m$ are constants. For a given concentration, the enhancement increases in the sequence RbI- $\mathrm{RbBr}-\mathrm{RbCl}$. This is shown to follow from Gilman's theory of impurity hardening. It is found that impurity hardening is more effective than solid solution hardening. 


\section{Acknowledgements}

The authors offer their grateful thanks to the referee for his constructive suggestions. Thanks are due to the University Grants Commission, New Delhi, for financing a project on the hardness studies of rubidium halides. (DBS) acknowledges financial support from the UGC in the form of an Emeritus Fellowship.

\section{References}

Armington A F, Posen H and Lipson H 1973 J. Electronic Mater. 2127

Bosch A V, Dresselaers J, Vansummeren J and Hovi M 1972 Phys. Status Solidi (a)11 479

Chin G Y, Van Uitert L G, Green M L, Zydzik G J and Kometani T Y 1973 J. Am. Ceram. Soc. 56369

Dryden J S, Marimoto S and Cook J S 1965 Philos. Mag. 10 379

Fleischer R L 1962 J. Appl. Phys. 333504

Gilman J J 1974 J. Appl. Phys. 45508
Haribabu V and Subba Rao U V 1984 Prog. Crystal Growth \& Charac. 18189

Shrivastava U C 1980 J. Appl. Phys. 511510

Sirdeshmukh D B and Srinivas K 1986 J. Mater. Sci. 214117

Sirdeshmukh D B, Subhadra K G and Kishan Rao K 2000 Bull. Mater. Sci. 23147

Sirdeshmukh D B, Sirdeshmukh L and Subhadra K G 2001a Alkali halides-A handbook of physical properties (Berlin: Springer Verlag)

Sirdeshmukh D B, Sirdeshmukh L, Subhadra K G, Kishan Rao K and Bal Laxman S 2001b Bull. Mater. Sci. 24469

Sirdeshmukh D B, Geeta Krishna P and Subhadra K G 2002 Bull. Mater. Sci. 25203

Srinivas K, Thirmal Rao T, Subhadra K G and Sirdeshmukh D B 1999 Phys. Edu. 16273

Subba Rao U V and Hari Babu V 1978 Pramana - J. Phys. 11 149

Subhadra K G, Balaiah E and Sirdeshmukh D B 2002 Bull. Mater. Sci. 2531

Thirmal Rao T and Sideshmukh D B 1991 Cryst. Res. Technol. 26 K53

Thomas M, Von Seggeren H and Winnacker A 1994 J. Appl. Phys. 761800 